\title{
Análise Temporal de Macro-habitat no Pantanal via Processamento de Fotografias Aéreas e Dados Obtidos por Sistemas de Aeronaves Remotamente Pilotadas
}

\author{
Gustavo Manzon Nunes ${ }^{1} \&$ Thais Marcela Duarte de Siqueira ${ }^{1}$
}

Recebido em 30/01/2018 - Aceito em 20/08/2019

RESUMO - As aplicações e a geração de produtos via sensoriamento remoto orbital para o mapeamento de áreas úmidas, devido à baixa resolução temporal e espacial, podem não gerar os resultados esperados, sobretudo em pequenas áreas. Sendo assim, este trabalho objetivou, com o uso de dados obtidos por um Sistema de Aeronave Remotamente Pilotada e de aeronave tripulada, analisar e caracterizar as mudanças temporais da paisagem no intervalo de 50 anos, em uma região do Pantanal de Poconé/MT, em nível de detalhe, bem com delimitar os macro-habitat existentes e dimensionar espacialmente a proliferação de espécies invasoras na região. Para a base de dados utilizada no estudo foram obtidas fotografias aéreas com aeronave tripulada da Força Aérea Americana (USAF), que realizou voos na região do Pantanal nos anos de 1965/1966. Como base de dados atual, foram programadas missões com um Sistema de Aeronave Remotamente Pilotada (RPAS) de asa fixa, modelo ECHAR 20B, no mês de agosto de 2015. A partir da obtenção dos dados, foram realizados processamentos digitais e calibrações geométricas necessárias para a comparação temporal dos dados obtidos em 1965/1966 (USAF) e 2015 (RPAS). Posteriormente, no software eCognition Developer foi feita a segmentação e a Análise de Imagens Baseada em Objetos (OBIA), sendo adotados, como parâmetros, regras de classificação, algoritmos existentes no software e também o Índice de Vegetação por Diferença Normalizada. Por meio dos resultados obtidos, foi possível delimitar os macro-habitat existentes e verificar as alterações na paisagem no período de 50 anos. Quantificaram-se e qualificaram-se as modificações específicas e estruturais causadas pela expansão de espécie arbustiva/ arbórea na área, envolvendo principalmente Combretum spp. (Pombeiro) e, em alguns locais, Voshysia divergens (Cambará). As análises temporais, o uso de OBIA e o advento de sensores acoplados em RPAS para a realização de aerolevantamentos apresentaram resultados compatíveis com escalas de 1:1000. Os resultados fornecem subsídios que auxiliam no entendimento da dinâmica de áreas no Pantanal e seus macro-habitat, além de permitirem avanços na fronteira geotecnológica para desenvolvimento de novos estudos em outras regiões, tendo-se em vista os padrões em termos de resolução espacial e temporal.

Palavras-chave: RPAS; invasão; Combretum spp.; OBIA.

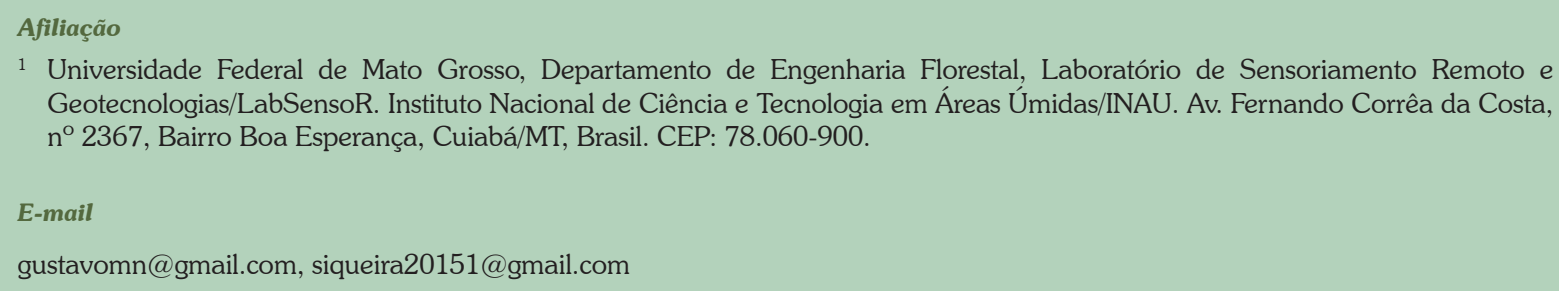


ABSTRACT - Temporal Analysis of Macrohabitats in the Pantanal via Aerial Photography Processing and Data from Remote Piloted Aircraft Systems. Applications and product generation by orbital remote sensing for the mapping of wetlands due to low temporal and spatial resolution may not yield the expected results, especially in small areas. Thus, this work aimed to use data obtained by a Remotely Piloted Aircraft System and manned aircraft to analyze and characterize the landscape changes over 50 years, in a region of the Pantanal of Poconé/MT in detail level, as well as delimit the existing macrohabitats and spatially dimension the advance of Encroaching Species in the study area. For the database used in the study, aerial photographs were obtained with manned aircraft of the American Air Force (USAF), which carried out flights in the Pantanal Region in the years 1965/1966. As a current database, missions were programmed with a Remotely Piloted Aircraft Systems (RPAS), of the fixed wing model ECHAR 20B in August 2015. From the data collection, digital processing and geometric calibrations were performed temporal comparison of data obtained in 1965 (USAF) and 2015 (RPAS). Later, in the eCognition Developer software segmentation and Object-based Image Analysis (OBIA) in both data (USAF and RPAS), classification parameters, algorithms in the software were used as parameters and also the Normalized Difference Vegetation Index adapted to RPAS data. Through the results obtained, it was possible to delimit the existing macrohabitats and to verify the changes in the landscape in the period of 50 years. The specific and structural changes caused by the expansion of shrub / tree species in the area were quantified and qualified, mainly involving Combretum spp. (Pombeiro) and in some places Voshysia divergens (Cambará). The temporal analyzes, the use of OBIA and the advent of sensors coupled in RPAS for aerial surveys, presented excellent results compatible with scales of 1: 1000 , providing subsidies that helped to understand the dynamics of the areas in the Pantanal and its macrohabitats, besides allowing advances in the geotechnical frontier for the development of new studies considering the standards in terms of spatial and temporal resolution.

Keywords: RPAS; encroachment; Combretum spp.; OBIA.

RESUMEN - Análisis temporal de macrohábitats en el Pantanal mediante procesamiento de fotografía aérea y datos de sistemas de aeronaves pilotadas a distancia. Las aplicaciones y la generación de productos a través de teledetección orbital para mapear humedales debido a la baja resolución temporal y espacial pueden no producir los resultados esperados, especialmente en áreas pequeñas. Por lo tanto, este trabajo tuvo como objetivo utilizar los datos obtenidos por un Sistema de Aeronaves Pilotadas a Distancia y aeronaves tripuladas para analizar y caracterizar los cambios en el paisaje durante los últimos 50 años en una región del Pantanal de Poconé/MT en nivel de detalle, así como definir los macrohábitats existentes y espacialmente escalar la proliferación de especies invasoras en la región. Para la base de datos utilizada en el estudio, se obtuvieron fotografías aéreas con avion tripulado de la Fuerza Aérea Americana (USAF), que realizaron vuelos en la región del Pantanal en los años 1965/1966. Como base de datos actual, las misiones se han programado con un Sistema de Aeronave Remotamente Pilotada (RPAS) de ala fija, modelo ECHAR 20B en agosto de 2015. A partir de la obtención de procesamiento de datos digital y se realizaron calibraciones geométricas necesarias para comparación temporal de los datos obtenidos en 1965/1966 (USAF) y 2015 (RPAS). Más tarde, em el software eCognition Developer se llevó a cabo la segmentación y Análisis de Imágenes Basado en Objetos (OBIA), se adoptó como parámetros de las reglas de clasificación, los algoritmos existentes en el software y también la diferencia normalizada índice de vegetación. A través de los resultados obtenidos, fue posible delimitar los macrohábitats existentes y verificar los cambios en el paisaje en el período de 50 años. Los cambios específicos y estructurales causados por la expansión de especies de arbustos / árboles en el área se cuantificaron y calificaron, involucrando principalmente a Combretum spp. (Pombeiro) y en algunos sitios Voshysia divergens (Cambará). El análisis temporal, el uso de OBIA y la llegada de sensores acoplados en RPAS para realizar mapeos, presentaron resultados compatibles con escalas de 1:1000. Los resultados proporcionan subsidios que ayudan en la comprensión de las áreas dinámicas en el Pantanal y sus macrohábitats, además de permitir avances en la frontera geotecnológica para el desarrollo de nuevos estudios en otras regiones, teniendo en cuenta las normas en términos de resolución espacial y temporal.

Palabras clave: RPAS; invasion; Combretum spp; OBIA.

\section{Introdução}

O Pantanal é considerado uma das mais extensas áreas úmidas do mundo (Zedler \& Kercher 2005). No Brasil, alcança uma área de, aproximadamente, $150.355 \mathrm{~km}^{2}$, localizados no sul de 
Mato Grosso e no noroeste de Mato Grosso do Sul (IBGE 2004). Os pulsos de inundação no Pantanal são periódicos e previsíveis, gerando adaptações e estratégias nos organismos que utilizam de forma eficiente os atributos desse ambiente. O pulso de inundação é considerado a força motriz que mantém um equilíbrio dinâmico nas planícies de inundação (JUNK et al. 1989, 2005)

As distintas pastagens nativas no Pantanal são sustentáveis quando conseguem manter sua estrutura e diversidade, sua autonomia ao longo do tempo e sua resiliência (capacidade de recuperação) diante dos distúrbios naturais e antrópicos. A intensidade e frequência dos distúrbios naturais (ex. seca, inundação, fogo) e antrópicos (ex. uso do fogo, taxa de lotação animal, métodos de controle/limpeza) podem causar modificações no ecossistema e produzir também ambientes favoráveis para a disseminação de plantas não desejáveis, consideradas invasoras. Portanto, as mudanças na estrutura da vegetação são indesejáveis devido aos impactos econômicos e ecológicos nos ecossistemas, tais como a diminuição de campos naturais de pastagens e a homogeneização das comunidades de plantas (Santos et al. 2006). Por outro lado, Nunes da Cunha \& Junk (2004) mostram que eventos climáticos plurianuais de seca e umidade têm efeitos naturais sobre a expansão ou retração da vegetação pantaneira; isso indica a característica de desenvolvimento muito dinâmico das comunidades de plantas nos ambientes de áreas úmidas (AUs).

Analisando as possibilidades de caracterização do Pantanal, destaca-se o uso de Sistemas de Aeronaves Remotamente Pilotadas como importante opção para a delimitação de AUs. Essa tecnologia possui baixo custo de operação, flexibilidade da programação de voos e baixa altitude de voos, o que proporciona a obtenção de dados de altíssima resolução temporal e espacial, sendo uma alternativa para o monitoramento do ambiente (Turner et al. 2012).

\section{Sistemas de Aeronaves Remotamente Pilotadas e uso na análise da cobertura vegetal}

Segundo Nunes et al. (2014), o advento de novas tecnologias, como a utilização de Sistemas de Aeronaves Remotamente Pilotadas, primeiramente alavancado com o uso militar, tem atingido maturidade e já vem possibilitando aplicações para uso comercial e civil. Dentre os vários avanços que estão sendo incorporados em RPAS, podem-se elencar melhorias nos sistemas de orientação, confiabilidade e durabilidade da plataforma, câmeras e sensores customizáveis, inovações em hardware e software, além de opções no uso de baterias mais duráveis. Essas melhorias tecnológicas, combinadas com uma diminuição nos custos de componentes eletrônicos, apresentam uma oportunidade fantástica para aplicações de dados obtidos por Veículos Aéreos Não Tripulados (VANTs) na análise de recursos naturais.

Tratando-se do uso de sensores remotos para a aquisição de dados espaciais e ambientais, é possível a utilização de dois tipos de sensores, sendo eles sensores ativos ou sensores passivos. Os sensores ativos possuem a própria fonte de energia, que interage com alvos, sendo possível obter informações das propriedades físicas (rugosidade e geometria) e elétricas (condutividade, que depende da porosidade e do conteúdo em água) dos materiais. Já os sensores passivos dependem da energia solar para aquisição de informações, sendo que, a partir da energia solar refletida ou da energia térmica emitida de alvos, é possível obter informações sobre as propriedades químicas dos materiais (Nunes 2017).

A obtenção de fotografias aéreas de alta resolução possui várias aplicações no manejo da vegetação, tais como monitoramento da dinâmica da vegetação, análise da ciclagem de nutrientes e energia, distinção de processos erosivos e desertificação, desenvolvimento de práticas de manejo de pastagens nativas determinando suas condições e avaliando a eficácia de técnicas de manejo e controle de pragas e plantas daninhas (Rango et al. 2006, Breckenridge et al. 2011).

Breckenridge et al. (2011) avaliaram a viabilidade do uso de RPAS para coleta de imagens úteis na discriminação de seis tipos de cobertura do solo (arbustos, arbustos mortos, gramíneas, 
herbáceas, serrapilheira e solo exposto) em ecossistemas estépicos nos Estados Unidos, utilizando plataformas de asa fixa e multirotor. Para correlação dos dados obtidos em campo com dados extraídos da imagem sobre cobertura de vegetação, foram instaladas parcelas em campo para coleta dos dados. As estimativas de campo mostraram boa concordância para as classes mapeadas, e o estudo concluiu que, para um melhor detalhamento e precisão, é desejável utilizar um RPAS multirotor, mas se o objetivo da coleta de dados é avaliar mudanças no nível da paisagem em larga escala, a coleta mais apropriada é a partir do uso de um sistema de asa fixa.

\section{Análise de Imagens Baseadas em Objetos (OBIA)}

As primeiras classificações automáticas de imagens de sensoriamento remoto consideravam o valor digital observado em cada pixel. No início da década de 1980, foram criados métodos de classificação de imagens baseados em regiões, isto é, agrupamentos de pixels próximos, também denominados segmentos, segundo critérios de semelhança do valor digital e obedecendo a limiares de área.

Com o avanço na resolução espacial das imagens, em conjunto com o avanço da resolução espectral, surgiram demandas para o aprimoramento das ferramentas computacionais e estratégias para a análise das imagens (Maktav 2005 apud Carvalho 2011), em especial para a classificação de imagens, levando-se em consideração outros parâmetros, como a forma dos alvos e as relações existentes entre o alvo e seus vizinhos.

Neste contexto surge o termo GEOBIA (Geographic Object-Based Image Analysis), que foi construído no paradigma da análise baseada em objetos, e tem a segmentação como componentechave na sua análise. Nesse tipo de análise, um determinado problema é representado por um conjunto de objetos que possuem características próprias e interagem entre si. Objetos com as mesmas características são agrupados em classes organizadas, que se encontram em níveis diferentes, formando uma hierarquia, ou seja, as classes de níveis inferiores formam as subclasses que herdam características da superclasse de nível superior (Pinho et al. 2009).

Portanto, o objetivo principal do presente trabalho é estudar o uso de fotografias aéreas obtidas por aeronave tripulada e pelo uso de RPAS, visando delimitar os macro-habitat e a proliferação de espécies arbustivas/arbóreas na área de estudo, com o uso de algoritmos e índice de vegetação, e, por fim, realizar a análise temporal que envolve os anos de 1965/1966 e 2015 na região do Pantanal de Poconé/MT, que poderá servir de modelo para replicação em outras áreas úmidas.

\section{Material e métodos}

\section{Caracterização da área de estudo}

O estudo foi realizado em uma área entre as coordenadas $16^{\circ} 00^{\prime}-17^{\circ} 38^{\prime} \mathrm{S}$ e $55^{\circ} 59^{\prime} 46^{\prime \prime}$ -57 38' 38”W na Rodovia MT - 370, totalizando 932,88ha, próxima ao município de Poconé, na região do Pantanal Matogrossense (Figura 1). O Pantanal de Poconé é formado pelas bacias dos rios Cuiabá, Bento Gomes e Paraguaizinho (Adámoli 1982). Caracteriza-se por apresentar geomorfologia compreendida por planícies de inundação, vazantes e corixos, sendo que estes últimos recebem água do rio Cuiabá durante as enchentes e são os maiores responsáveis pelo alagamento da planície compreendida entre os rios Cuiabá e Paraguai (Amaral 1987).

O clima da região é do tipo Aw de Köppen, ou seja, quente e úmido (Amaral Filho 1986). O regime das chuvas é tropical, com duas estações bem definidas, uma seca e outra chuvosa. A precipitação média anual é de $1.384 \mathrm{~mm}$ (Almeida 1998). O período de inundação normalmente ocorre entre janeiro e abril, juntamente com a estação chuvosa (Rebellato \& Nunes da Cunha 2005). 


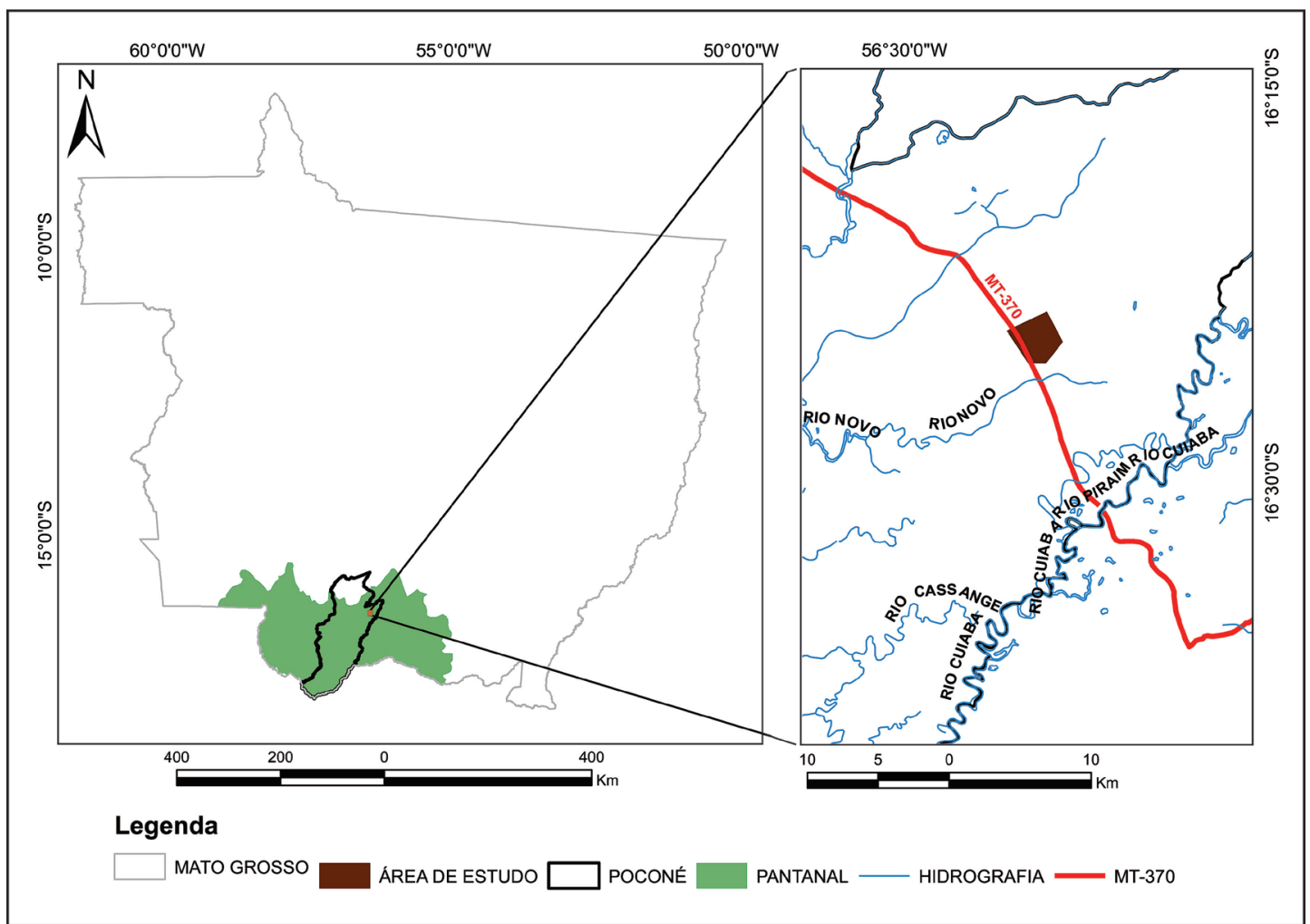

Figura 1 - Localização da área de estudo.

\section{Métodos}

Para a realização do trabalho foram adotados os procedimentos metodológicos detalhados na sequência, que possibilitaram viabilizar a discriminação de macrohabitat $e$ a análise temporal comparativa na área de estudo, com dados de fotografias aéreas pretéritas (missões da USAF -1965/1966) e dados atuais (missões de voo com RPAS, em 2015).

Os dados aerofotogramétricos pretéritos foram obtidos junto ao acervo da Companhia de Pesquisa de Recursos Minerais (CPRM), adquiridos por câmera métrica de aeronave da Força Aérea Americana (USAF), gerados na escala de 1:60.000, nos anos de 1965/1966. As fotografias adquiridas foram reveladas de negativos e em filmes, gerando fotos em níveis de cinza (P/B) na mesma área de estudo deste trabalho. Essas fotografias foram digitalizadas do formato analógico com a dimensão de $23 \mathrm{~cm} \times 23 \mathrm{~cm}$. No Adobe Photoshop CS3 aplicou-se o efeito contraste, resultando em uma maior qualidade da imagem. No software ArcMap, foi realizada a composição de bandas e, na sequência, sua correção geométrica, utilizando-se dados SPOT com 2,5m de resolução espacial como base para a correção. Posteriormente foi utilizado ortomosaico gerado pelo RPA para melhor calibração geométrica da fotografia.

Foram programadas duas missões de voo para a aquisição dos dados com a RPA de asa fixa, modelo ECHAR 20B (Figura 2), tendo em vista a autonomia de voo para o recobrimento da área de estudo (1 hora por voo). A plataforma foi composta por um módulo com sistema GPS, uma estação de controle e um terminal de dados que possibilitam seu monitoramento. O sensor acoplado no RPA foi uma câmera Canon EOS REBEL T3i 18MP, modificada de fábrica, configurada com distância focal de $28 \mathrm{~mm}$, com dois canais do espectro eletromagnético no visível (azul e verde) e infravermelho próximo (NIR). A câmera, utilizada por ter informações do espectro do infravermelho próximo, possibilita uma melhor extração de informações relacionadas com diferenças na cobertura vegetal. O lançamento do RPA foi via catapulta, e o pouso deu-se por meio de acionamento de paraquedas. 


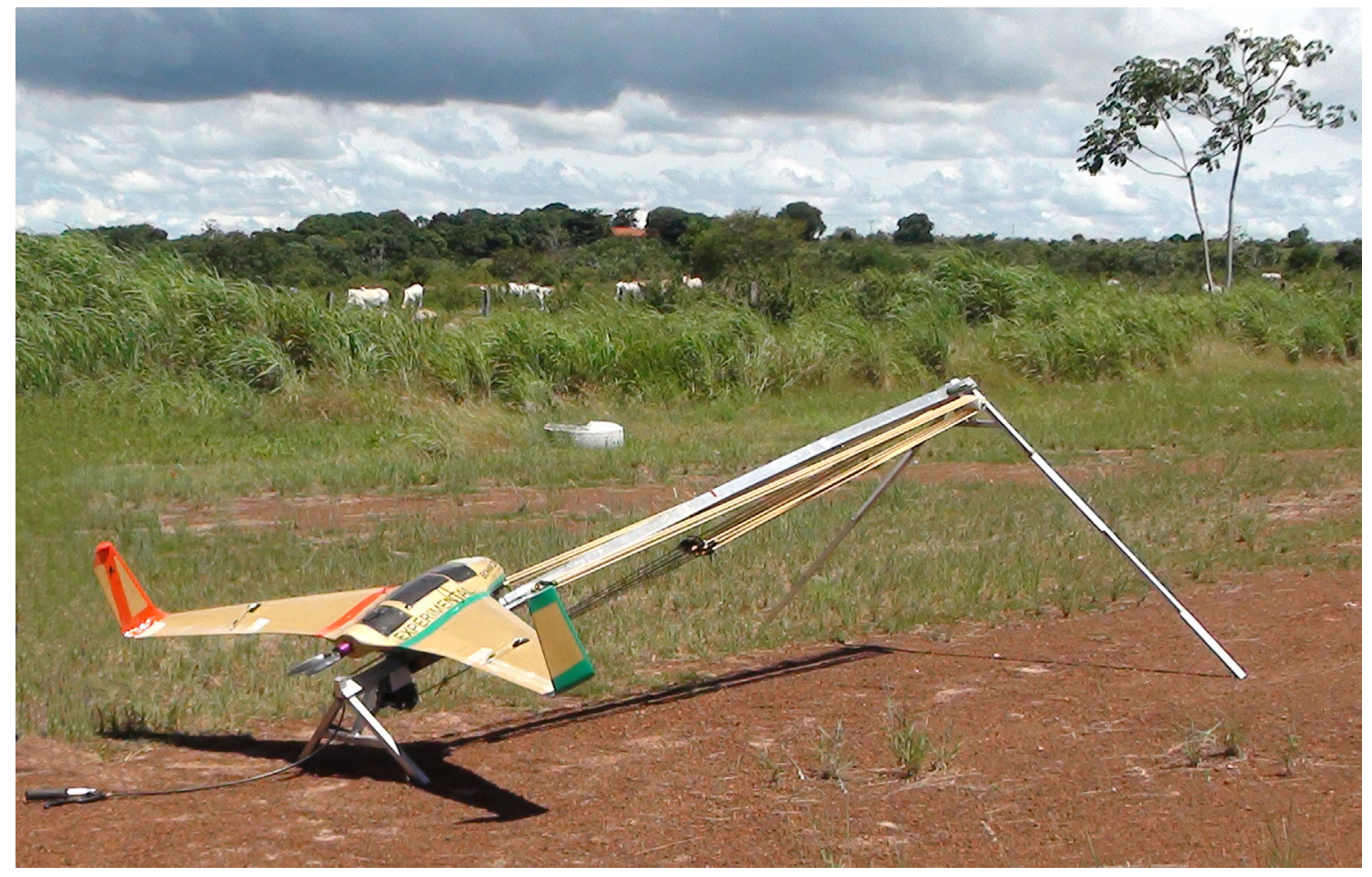

Figura 2 - RPAS ECHAR 20B preparada para decolagem acoplada na catapulta.

O planejamento das missões foi enviado e aprovado via emissão de NOTAM pelo Departamento de Controle do Espaço Aéreo (DECEA), sendo o polígono de voo devidamente cadastrado junto ao Sistema AISWEB. O NOTAM deriva do inglês "Notice To Airmen", ou seja, "Aviso aos Aeronavegantes". O seu objetivo é divulgar, antecipadamente, toda informação aeronáutica, bem como modificações de qualquer instalação, estabelecimento, serviço, procedimento ou perigo aeronáutico, cujo conhecimento seja essencial para a navegação aérea.

Os voos com o RPA ECHAR 20B foram realizados no dia 13 de agosto de 2015, com uma altura de $520 \mathrm{~m}$ do solo, recobrimento longitudinal de $70 \%$ e lateral de $65 \%$, possibilitando, assim, o alinhamento e a mosaicagem de todas as fotografias, evitando áreas sem dados obtidos. Antes da realização da missão, distribuíram-se por toda a área 18 pontos de controle terrestres (alvos) quadrangulares com $70 \times 70 \mathrm{~cm}$, pintados de preto e branco, para permitir sua visualização nas fotografias, tendo-se como base para a correção geométrica e ortorretificação. Após o voo, foram coletados os pontos de controle para a ortorretificação do mosaico, utilizandose o receptor GNSS de alta precisão (Topcon SR). Coletaram-se as coordenadas geográficas dos 18 pontos de controle distribuídos em toda área, que, posteriormente, foram pós-processadas em laboratório.

Na Figura 3, são apresentadas as cartas-imagem (USAF e RPA) relacionadas com a área em estudo, que totalizou 932,88ha.

\section{Processamento de dados obtidos pela RPA}

Para a geração do ortomosaico, foi utilizado o software Agisoft PhotoScan Professional (64 bits), que possui um fluxo automatizado para processar as imagens, utilizando, para isso, algoritmos de visão computacional, seguindo as fases descritas abaixo: 


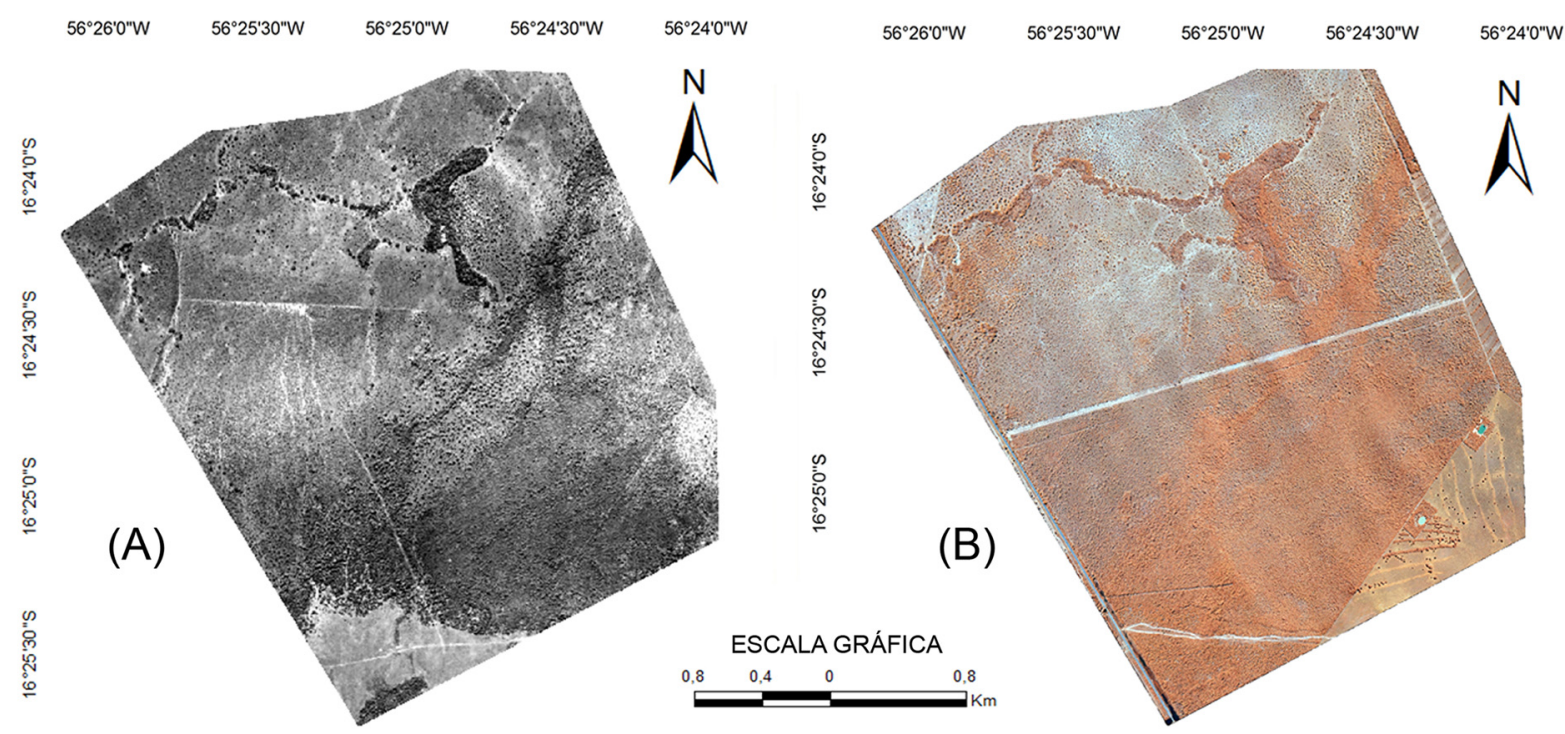

Figura 3 - Recorte da área de estudo - Projeto USAF (A) e ortomosaico da área de estudo - Missão com RPA ECHAR 20B (B).

- 1a: foram inseridas as fotografias, com suas respectivas coordenadas e seus ângulos de atitude (Pitch, Yaw e Raw);

- 2a: foi realizado o alinhamento das fotografias com o Agisoft PhotoScan, consistindo em encontrar os pontos correspondentes entre as fotografias, encontrando também a posição da câmera para cada foto; como resultado, obteve-se uma nuvem de pontos esparsos;

- 3a: foram inseridos os pontos de controle terrestre (18 alvos), usados para otimizar posições da câmera e dados de orientação, permitindo, assim, melhores resultados de referência do modelo;

- 4a: consiste na otimização do alinhamento da câmera para obtenção de uma maior precisão no cálculo de parâmetros internos e externos da câmera, como a correção de eventuais distorções;

- 5a: construção da nuvem de pontos densa, baseando-se nas posições estimadas e nos pontos esparsos; o programa calcula informações de profundidade a ser combinada em uma única nuvem densa de pontos. A partir dessa nuvem densa, é criada a malha irregular de triângulos, que representa as elevações da superfície, gerando, dessa forma, o Modelo Digital de Elevação (MDE); e

- 6a: exportação do MDE e ortomosaico no sistema de coordenada UTM, fuso 21 e no sistema de referência WGS84.

\section{Análise de imagens via OBIA}

Primeiramente foi realizada a segmentação das imagens (fotografia USAF e as obtidas pelo RPA) no software eCognition Developer, por meio do algoritmo Multiresolution Segmentation, que trabalha com valores dos atributos de cor, forma e escala. Para cada imagem, foi criado um projeto, onde foram realizadas algumas segmentações, buscando-se uma segmentação que melhor separasse os objetos das imagens. Abaixo está a Tabela 1, que mostra os parâmetros utilizados. 
Tabela 1 - Parâmetros utilizados na criação dos diferentes cenários de segmentação.

\begin{tabular}{|l|c|c|c|}
\multicolumn{1}{c|}{ Imagens } & Compacidade & Forma & Escalas \\
\hline Projeto USAF - 1965/1966 & 0,5 & 0,1 & $80,90,100$ \\
\hline Ortomosaico RPAS - 2015 & 0,5 & 0,1 & $50,80,100,120$ \\
\hline
\end{tabular}

Foi realizada a verificação da qualidade da segmentação por meio da análise visual, comparando as formas, tamanho e a representatividade dos objetos em relação aos diferentes tipos de vegetação existentes (compacidade).

A seguir, foram analisados e definidos os seguintes macrohabitats para mapeamento no Projeto USAF e Missão RPAS, sendo assim definidos no Projeto USAF: campo limpo - inundável, cordilheira, campos de murundus, área de arbustal - pombeiro (Combretum spp.) - área formada por alta densidade de pombeiro (Combretum spp.), área com expansão de arbustal (Combretum spp.) e solo exposto/estradas de terra. Para a Missão RPAS foram definidos: campo limpo inundável, cordilheira, campos de murundus, área de arbustal - pombeiro (Combretum spp.), solo exposto/estradas de terra e lâmina d'água.

Utilizou-se o algoritmo Manual Classification para a classificação dos dados USAF de 1965/1966, considerando que as informações obtidas foram advindas de cópia de fotografia de médio formato por scanner, em níveis de cinza, sem informações espectrais possíveis de serem exploradas no programa.

Já para os dados obtidos pelo RPAS, foi realizada a análise do ortomosaico no software eCognition Developer, através de algoritmos do programa, considerando regras de classificação $e$ associando informações de média de brilho, relação de borda entre as classes e com o uso do índice de vegetação NDVI, que foram utilizadas visando diferenciar os objetos para cada classe de referência. Para a definição das classes de lâmina d'água e solo exposto/estradas de terra, utilizouse o algoritmo média de brilho.

Foram utilizados parâmetros de associação e relações de borda entre as classes campo limpo - inundável e área de arbustal - pombeiro, visando-se diferenciar os campos de murundus que possuem agrupamento de árvores.

Ao final, exportaram-se os dados referentes a cada classe em formato vetorial e gerados os mapas temáticos em um sistema de informações geográficas, bem como foram quantificadas a área em hectares e a porcentagem de ocorrência de cada macro-habitat.

\section{Resultados e discussão}

Tendo em vista a dinâmica da paisagem na área e as mudanças ocorridas, verificou-se a proliferação, após o período de 50 anos, da espécie de Combretum spp., ocorrente na área, bem como o consequente acréscimo na formação do pombeiral. Além disso, existem no macro-habitat de campos de murundus indivíduos de $V$. divergens (Cambará), que é uma espécie exótica e invasora que se adaptou na região.

O termo encroachment é utilizado para caracterizar um aumento gradual na cobertura, densidade ou biomassa de plantas nativas ou arbustivas (Van Auken 2000, Eldridge et al. 2011, Barbosa da Silva et al. 2016). No caso apresentado neste artigo, verifica-se a conversão de habitat campestres naturais em arburtivos de Combretum spp., contribuindo para a retração da diversidade ecológica florística e faunística, aumentando, assim, a similaridade de comunidades vegetais. 
Os mapeamentos feitos neste estudo foram compatíveis com a escala de 1:1000, representando preliminarmente um grande avanço em estudos realizados no Pantanal, principalmente devido à sua complexidade de habitat de áreas úmidas.

A seguir, na Figura 4, é possível analisar a Carta Temática gerada para os anos de 1965/1966, a partir da metodologia apresentada.

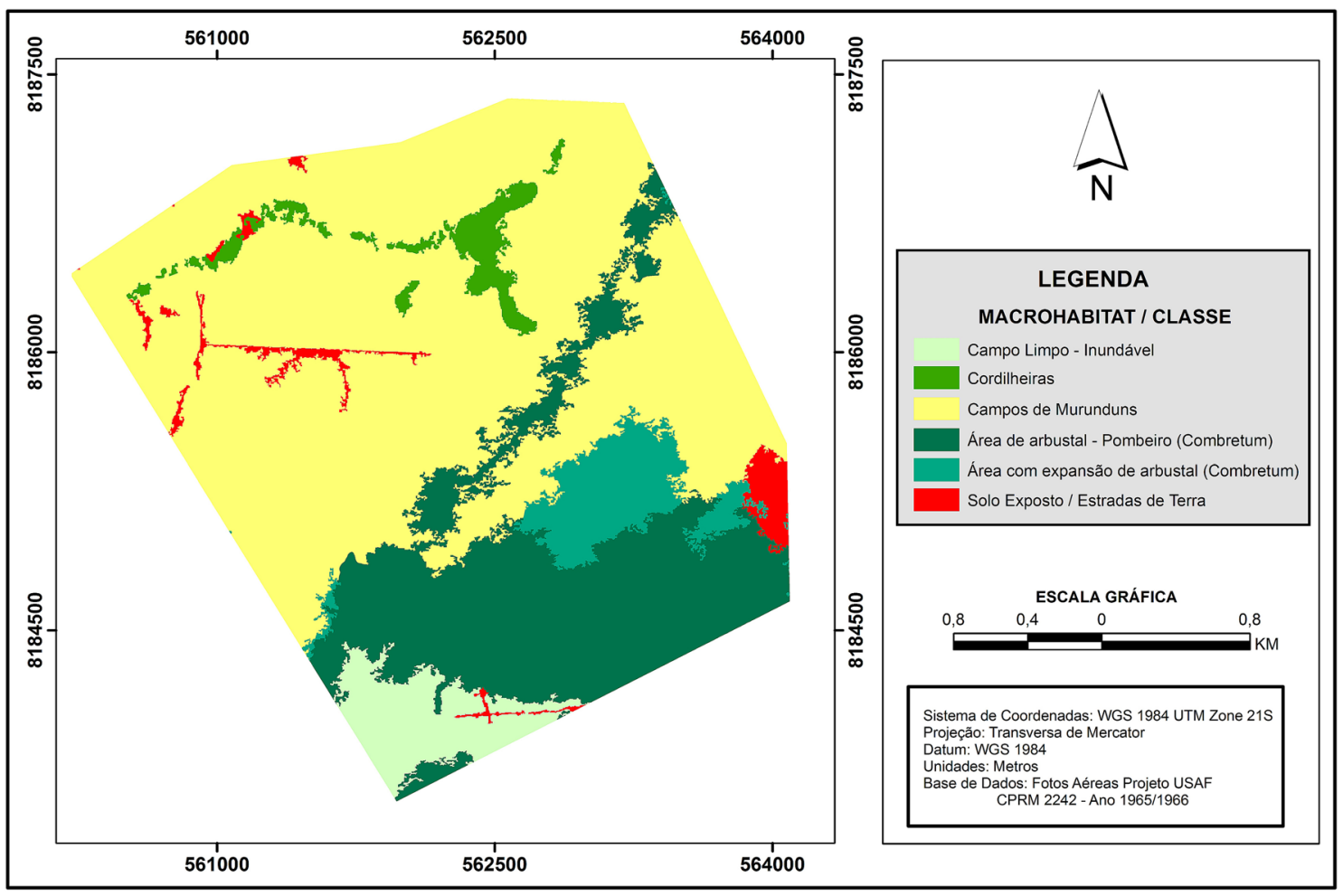

Figura 4 - Carta Temática - Projeto USAF, no período 1965/1966.

Após a realização de dois sobrevoos no dia 13 de agosto de 2015, foi obtido um total de 1.067 fotografias, bem como um ortomosaico de altíssima resolução, com GSD de $8 \mathrm{~cm}$ (tamanho do pixel), após o processamento dos dados que envolveu o alinhamento das fotografias, geração de nuvem esparsa, inserção dos pontos de controle, geração de nuvem densa e geração da malha.

Através dos processamentos e algoritmos utilizados no eCognition, foi possível obter a Carta Temática com os macro-habitat mapeados para o ano de 2015, conforme Figura 5.

$\mathrm{Na}$ Tabela 2 , encontram-se quantificadas as áreas, em hectares e porcentagens de ocorrência, dos macro-habitat da área em estudo.

$\mathrm{O}$ que mais chama a atenção, espacialmente analisando o mapeamento temporal e a comparação da Tabela 2, é o grande incremento entre o período de 1965/1966 a 2015 das áreas dominadas por Combretum spp. (pombeiral). Essas áreas estão associadas à expansão de espécies arbustivas/arbóreas que acabam invadindo áreas inicialmente de campo limpo natural, tornando-se um ambiente de pombeiro denso (fechado ou "grosso") que avançou sobre zonas de transição aquático/terrestre (Aquatic/Terrestrial Transition Zones - ATTZ) no Pantanal, ao longo de períodos plurianuais de inundação. 


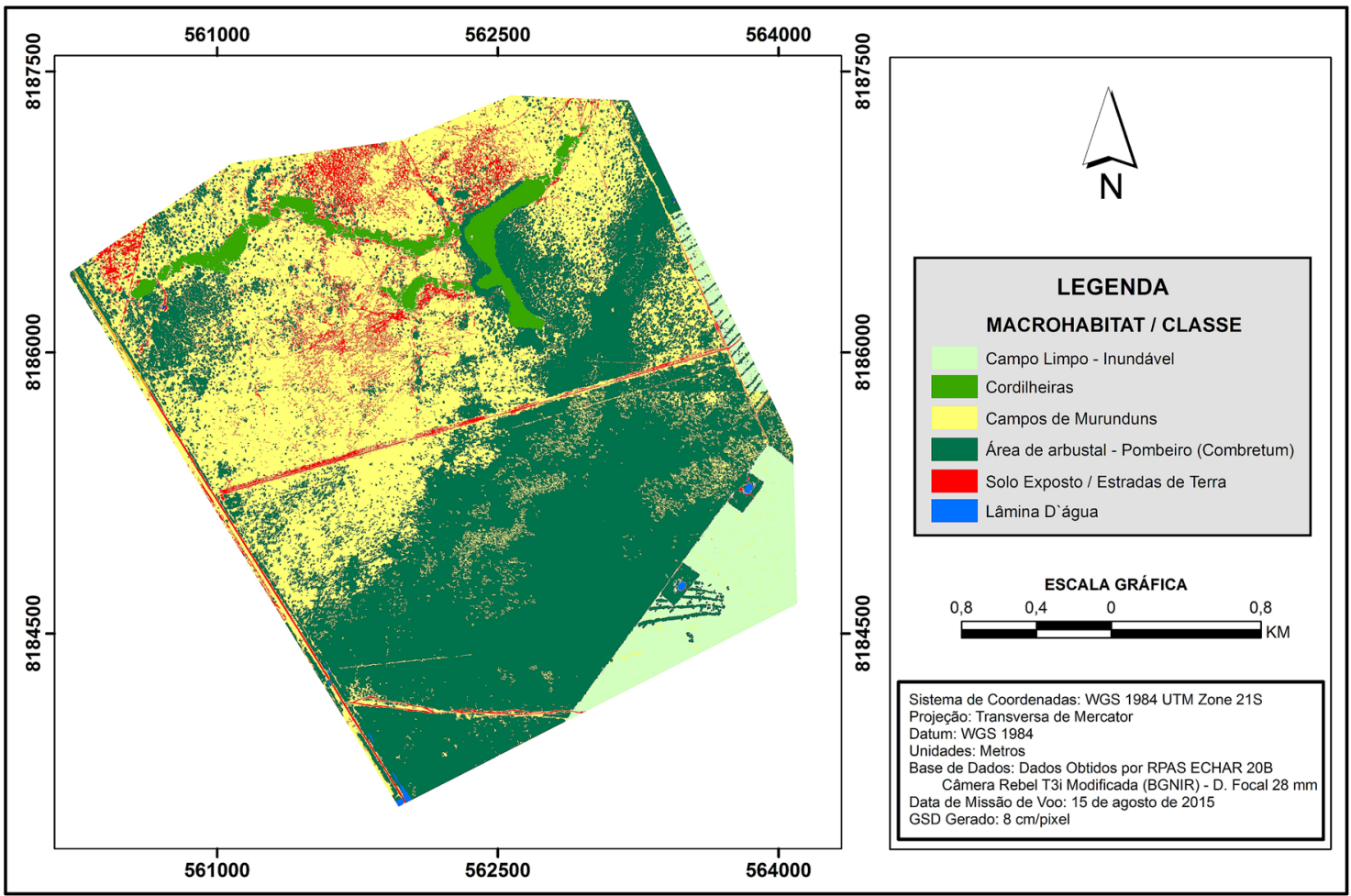

Figura 5 - Carta Temática - Missões com RPA ECHAR 20B, ano 2015.

Tabela 2 - Macro-habitat e porcentagem associados ao mapeamento, com dados da USAF e do RPAS.

\begin{tabular}{|l|c|c|c|c|}
\multirow{2}{*}{\multicolumn{2}{|c|}{ MACROHABITAT }} & \multicolumn{2}{|c|}{ USAF (1965/1966) } & \multicolumn{2}{c|}{ RPAS (2015) } \\
\cline { 2 - 5 } & Área (ha) & \% & Área (ha) & $\%$ \\
\hline Campo limpo - inundável & 44,40 & 4,76 & 69,84 & 7,49 \\
\hline Cordilheiras & 24,70 & 2,65 & 27,68 & 2,97 \\
\hline Campos de murundus & 579,80 & 62,15 & 357,58 & 38,33 \\
\hline Área de arbustal - pombeiro (Combretum spp.) & 213,66 & 22,90 & 431,03 & 46,20 \\
\hline Área com expansão de arbustal (Combretum spp.) & 50,21 & 5,38 & - & - \\
\hline Solo exposto/estradas de terra & 20,11 & 2,16 & 45,55 & 4,88 \\
\hline Lâmina d'água & - & - & 1,20 & 0,13 \\
\hline TOTAL & $\mathbf{9 3 2 , 8 8}$ & $\mathbf{1 0 0}$ & $\mathbf{9 3 2 , 8 8}$ & $\mathbf{1 0 0}$ \\
\hline
\end{tabular}

A área de arbustal - pombeiro (Combretum spp.) dobrou praticamente de área, de 1965/1966 para o ano de 2015, representando 46,20\% da área total.

Como consequência do aumento da área de arbustal - pombeiro (Combretum spp.), a classe de campos de murundus se retraiu de $62,15 \%$ para $38 \%$ da área total, ou seja, o pombeiro avançou ao longo desse gradiente. 
Em estudo realizado por Silva (2011), envolvendo a colonização de campos nativos pelo aumento da expansão de Combretum laxum e a formação de estande monoespecífico, concluiu-se que ocorre perda de diversidade no habitat campestre e substituição dessas espécies por espécies associadas ao novo habitat, o que pode indicar que possíveis distúrbios plurianuais de inundação permitem uma boa capacidade de colonização de $C$. laxum sobre áreas de campos. Esses aspectos podem interferir perda de riqueza de espécies, na fauna e no uso da pecuária.

Uma das alternativas para controlar a expansão e a proliferação de espécies como Combretum sp., que acabam colonizando e se estabelecendo no ambiente de áreas úmidas, impedindo a utilização da área para outros fins da propriedade como a pecuária extensiva bem manejada, seria a realização de um correto plano de manejo, aliando os esforços na área ambiental e na política estadual, bem como junto a proprietários rurais pantaneiros. Ressalte-se que para a conversão e limpeza de pastagens no Pantanal é necessária a devida autorização pelo órgão ambiental estadual; no caso, a Secretaria Estadual do Meio Ambiente/MT.

Na região existente a sudeste da Carta Temática de 2015, pode-se observar que ocorreu a limpeza do pombeiral, onde, inclusive, se visualizam leiras formadas por resíduos referentes à retirada de Combretum spp. para posterior queima.

Segundo pesquisas, os macro-habitat distribuem-se em um gradiente de inundação, sendo as áreas cobertas com Cerrado sensu lato as mais elevadas (Nunes da Cunha, Junk 2001), diminuindo o gradiente para formações campestres até pântanos de plantas herbáceas (brejos) (Costa et al. 2010).

Deve-se salientar que ambos dados analisados foram obtidos durante a época de seca; porém, na época de cheia, toda a área encontra-se alagada, sendo muito difícil o acesso via carro ou caminhonete. Na Figura 6, que foi adquirida na área de estudo em março de 2017, a partir de RPA Multirotor DJI Phantom 4, pode-se verificar o padrão de inundação da área com pombeiral.

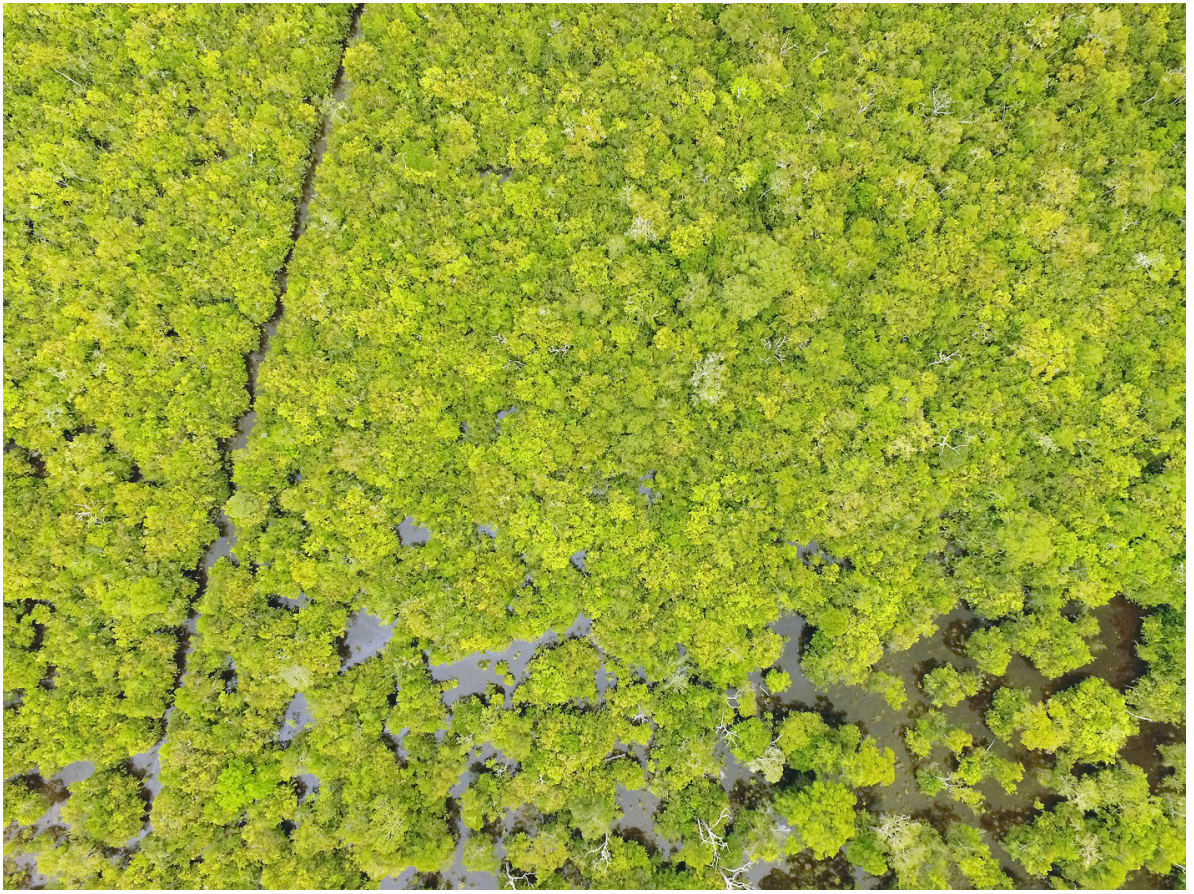

Figura 6 - Fotografia feita em área com pombeiro, via DJI Phantom 4. 
Outro produto possível de produzir subsídios para a análise estrutural da cobertura vegetal e habitat em áreas úmidas é a nuvem de pontos densa gerada pelo processamento de dados obtidos pelo RPA. Conforme a Figura 7, pode-se verificar a estratificação e a secção transversal extraída da área em estudo, onde se visualiza a altura dos indivíduos arbóreos (entre 10 e 18 metros) e de áreas com mais densidade de espécies.

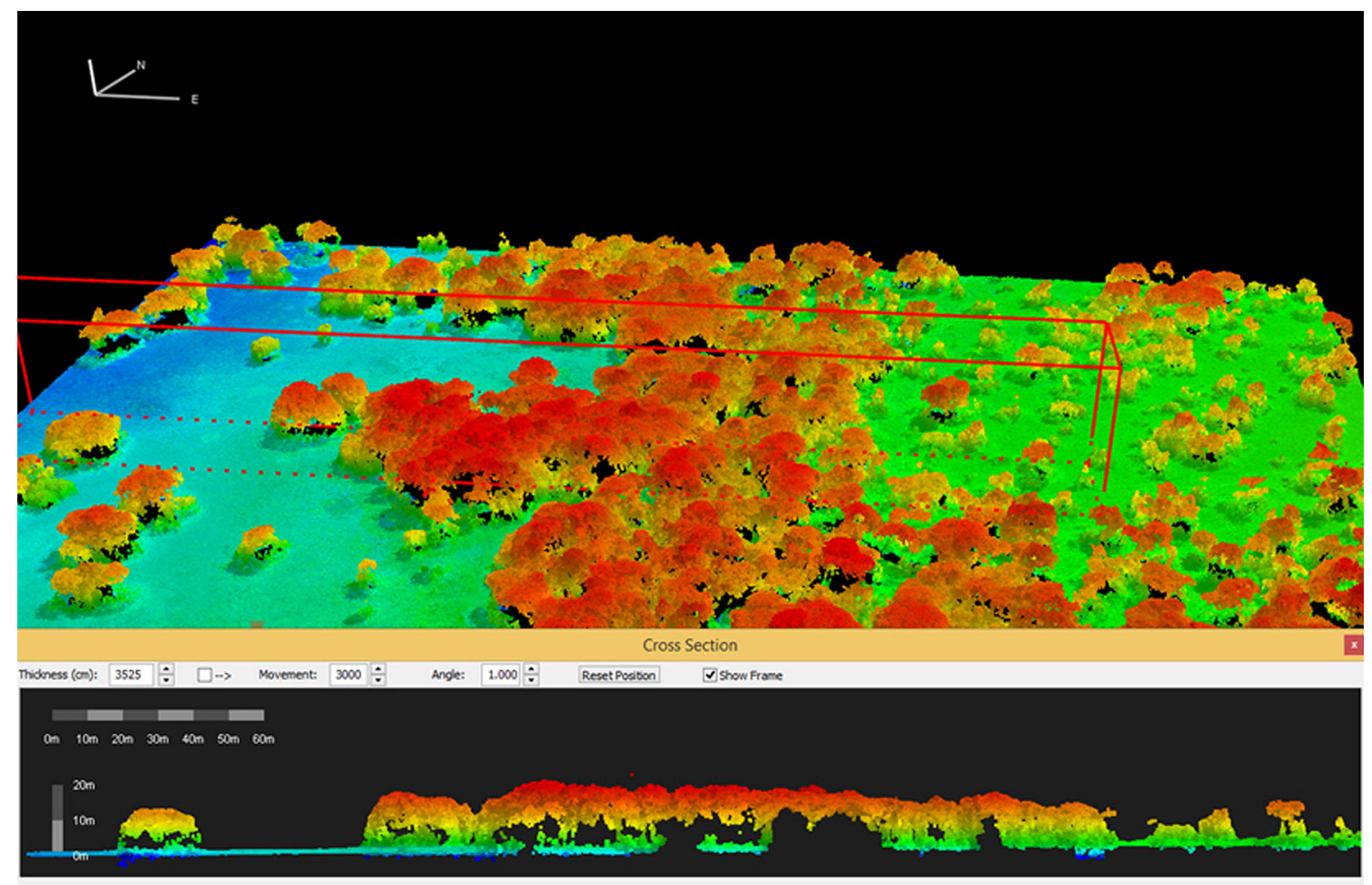

Figura 7 - Perfil tridimensional acima e, logo abaixo, representação da secção transversal com a altura e estrutura da vegetação na área em estudo.

Apesar da baixa qualidade da fotografia de 1966, foi possível gerar uma segmentação que melhor representasse a área, justificando a boa classificação e separação adequada dos macro-habitat presentes na cena de 1965/1966.

Para a delimitação das classes de solo exposto/estradas de terra e lâmina d'água, foi utilizada a média do brilho do canal do infravermelho próximo relacionado com a data de 2015. Foi necessária a aplicação de diferentes intervalos espectrais para delimitação dessa classe junto ao ortomosaico. Essas diferenças se justificam pela presença de elementos na água que podem alterar sua reflectância. Observando as imagens do ortomosaico, é visível a diferença na coloração das áreas com presença de água; já nas áreas de brejo, nota-se presença de vegetação sobre elas, resultando em uma confusão com o macro-habitat área de arbustal - pombeiro.

O Índice de Vegetação por Diferença Normalizada (NDVI) modificado, aplicado em dados do ano de 2015, apresentou as seguintes características: os valores de índice $>=0,29$ concentraram a classe de arbustal - pombeiro; já as áreas de campo limpo - inundável concentraram-se entre $>0,12$ a $<0,29$, enquanto que as áreas de solo exposto/estradas de terra se concentraram nos valores iguais ou menores que 0,139 . Em geral, o NDVI varia entre $-1,0 e+1,0$; para a vegetação, este índice varia entre, aproximadamente, zero e $+1,0$. Há, na literatura, autores que citam o NDVI para a vegetação variando entre intervalos mais restritos, como Fontana (2011), que cita o intervalo entre 0,3 e +1,0, e Ponzoni e Shimabukuro (2010), que cita intervalo entre, aproximadamente, 0,00 e 0,80 , sendo valores semelhantes aos encontrados neste trabalho. 


\section{Conclusões}

O uso de RPAS para a realização de aerolevantamentos e mapeamentos preenche uma lacuna deixada pelos métodos tradicionais, tratando-se, principalmente, de áreas consideradas de difícil acesso, como as encontradas no Pantanal, sobretudo em períodos de cheia/inundação.

Estudos aplicados em AUs são imprescindíveis por possibilitarem exploração de novos horizontes relacionados com padrões em termos de resolução espacial e temporal. Ao analisar dados pretéritos (1965/1966) e mais atuais (2015) apresentados neste estudo, foi possível realizar um diagnóstico do ambiente, qualificando e quantificando a dinâmica da paisagem.

Os processamentos e o uso de OBIA apresentaram excelentes resultados, tendo em vista o mapeamento e a comparação das duas épocas analisadas.

Na dinâmica da vegetação que ocorre na região estudada do Pantanal de Poconé/MT, ao analisar a delimitação de macro-habitat e o uso do solo nos anos de 1965/1966 e 2015, houve alterações na composição da paisagem, indicando um grande incremento no macro-habitat de pombeiro (Combretum spp.). O avanço desta espécie oportunista necessita ser mais estudado, pois contribui para mudanças em termos ecológicos e econômicos, com diminuição da presença de algumas espécies da fauna silvestre específicas de áreas de campo limpo, reduzindo pastagens e afetando a pecuária e a locomoção do gado.

Com a base aerofotogramétrica e as informações obtidas do RPA, foi possível gerar Cartas Temáticas e análises em ambientes de áreas úmidas compatíveis com Nível 4, tendo-se em vista escalas de 1:30.000 a 1:500 (RPAS), o que pode ser consultado no Marco Metodológico para delimitação e mapeamento de AUs.

Por fim, conclui-se que as análises apresentadas podem servir de base para o planejamento de políticas públicas, ambientais e de manejo no Pantanal, além de possibilitar a replicação deste estudo em outras AUs.

\section{Agradecimentos}

Os autores agradecem ao Instituto de Ciência e Tecnologia em Áreas Úmidas (INAU), pelo apoio logístico e pelo financiamento de pesquisas realizadas no âmbito deste estudo. Também ressaltamos o apoio do Conselho Nacional de Desenvolvimento Científico e Tecnológico (CNPq) no fornecimento de bolsa PIBIC para a coautora. Este trabalho também só foi possível com o auxílio e o fornecimento de dados em acervo e fotografias aéreas do Projeto USAF pela Companhia de Pesquisa de Recursos Minerais (CPRM).

\section{Referências bibliográficas}

Adámoli, J.A. 1982. O Pantanal e suas relações fitogeográficas com os cerrados: discussão sobre o conceito de complexo do Pantanal, p. 109-119. In: Anais do $\mathbf{3 2}^{\circ}$ Congresso Nacional da Sociedade Botânica do Brasil.

Amaral, J.A.M. 1987. Solos do Pantanal, p. 19-22. In: Recursos Forrageiros Nativos do Pantanal Matogrossense. EMBRAPA. 339p.

Amaral Filho, Z.P. 1984. Solos do Pantanal MatoGrossense, p. 91-96. In: 10 Simpósio sobre Recursos Naturais e Socioeconômicos do Pantanal. 265p.

Almeida, N.N. 1998. Estrutura e dinâmica de uma comunidade de plântulas em uma floresta sazonalmente inundável no Pantanal de Poconé, MT. Dissertação (Mestrado em Ecologia e Conservação da Biodiversidade). Universidade Federal de Mato Grosso. 93p. 
Barbosa da Silva, F.H.; Arieira, J.; Parolin, P.; Nunes da Cunha, C. N. \& Junk, W.J. 2016. Shrub encroachment influences herbaceous communities in flooded grasslands of a neotropical savanna wetland. Applied Vegetation Science, 19(3): 391-400.

Breckenridge, R.P. et al. 2011. Comparison of unmanned aerial vehicle platforms for assessing vegetation cover in Sagebrush Steppe ecosystems. Rangeland Ecology \& Management, 64(5): 521-532, doi:10.2111/REM-D-10-00030.1.

Carvalho, M.V.A. 2011. Classificação da cobertura e uso do solo com imagens WorldView-2 utilizando mineração de dados e análise baseada em objetos. Dissertação (Mestrado em Sensoriamento Remoto). Instituto Nacional de Pesquisas Espaciais. 179p.

Costa, C.P.; Cunha, C.N. \& Costa, S.C. 2010. Characterization of the flora and structure of the shrub-tree layer in a cerrado area in Pantanal do Poconé, MT. Biota Neotropical, 10: 61-73.

Eldridge, D.J.; Bowker, M.A.; Maestre, F.T.; Roger, E.; Reynolds, J.F. \& Whitford, W.G. 2011. Impacts of shrub encroachment on ecosystem structure and functioning: towards a global synthesis. Ecology Letters, 14: 709-722.

Fontana, D.C. 2011. Comportamento espectral da vegetação. < http://www.ufrgs.br/leaa/arquivos/ aulas/SERP06/cultivos.pdf>. (Acesso em 15/04/2017).

IBGE. Mapa de biomas e vegetação. 2004. Disponível em: < http://www.ibge.gov.br/home/presidencia/ noticias/21052004biomashtml.shtm>. (Acesso em 30/02/2017).

Junk, W.J. 2005. Flood pulsing and linkages between terrestrial, aquatic and wetland system. Verh. Internat. Verein. Limnol., 29: 11-38.

Junk, W.J. et al. 1989. The flood pulse concept in river - floodplain systems. In: Proc Int Large River Symp (LARS). D.P. Dodge (ed). Canadian Journal of Fishers and Aquatic, 106: 110-127.

Moreira, M.A. 2005. Fundamentos de Sensoriamento Remoto e Metodologias de Aplicação. 3 ed. Universidade Federal de Viçosa. 320p.

Nunes, G.M.; Vieira, D.J.E. \& Carvalho, S.P.C. Avaliação preliminar de dados obtidos por VANT em talhão florestal clonal de Eucalyptus urograndis H13 no Estado de Mato Grosso. In: Anais XI SENGEF, XI Seminário de Atualização em Sensoriamento Remoto e Sistemas de Informações Geográficas Aplicados à Engenharia Florestal. 8p.

Nunes, G.M. 2017. Marco metodológico para delimitação e mapeamento de áreas úmidas, p. 44-53. In: Nunes da Cunha, C. et al. Marcos referenciais para a lei federal do Pantanal e gestão de outras áreas úmidas. Editora EdUFMT. 156p.

Nunes da Cunha, C. \& Junk, W.J. 2001. Distribution of wood plant communities along the flood gradient in the Pantanal of Poconé, Mato Grosso, Brazil. International Journal of Ecology and Environmental Sciences. 27p.

Nunes da Cunha, C. \& Junk, W. J. 2004. Year-to-year changes in water level drive the invasion of Vochysia divergens in Pantanal grasslands. Applied Vegetation Science, 7: 103-110.

Pinho, C.M.D. et al. 2009. Classificação de cobertura do solo de ambientes intra-urbanos utilizando imagens de alta resolução espacial e classificação orientada a objetos, p.1681-1684. In: Almeida, C.M.; Pisani, R.J. et al. Análise comparativa entre o método de classificação supervisionada Maxver e NDVI para classes de uso do solo. In: X Congreso Argentino de Ingeniería Rural y II del Mercosur, 2009. 1.211p.

Ponzoni, F.J. \& Shimabukuro,Y.E. 2010. Sensoriamento Remoto no Estudo da Vegetação. Ed. São José dos Campos: Parêntese. 128p

Rango, A. et al. 2006. Research Article: Using Unmanned Aerial Vehicles for Rangelands: Current Applications and Future Potentials. Environmental Practice, 8(03): 159-168.

Rebellato, L. \& Nunes da Cunha, C. 2005. Efeito do "fluxo sazonal mínimo da inundação" sobre a composição e estrutura de um campo inundável no Pantanal de Poconé, MT, Brasil. Acta Bot. Bras., 19(4): 789-799. 
Santos, S.A.; Nunes da Cunha, C.; Tomás, W.; Pinto de Abreu, U.G. \& Arieira, J. 2006. Plantas Invasoras no Pantanal: Como Entender o Problema e Soluções de Manejo por Meio de Diagnóstico Participativo, Boletim de Pesquisa e Desenvolvimento. EMBRAPA Pantanal. 45p.

Silva, F.H.B. 2011. Efeito da Invasão de Combretum laxum Jacq. (Combretaceae) em Comunidade de Campo Nativo do Pantanal de Poconé, Brasil. Dissertação (Mestrado em Ecologia e Conservação da Biodiversidade). Universidade Federal do Mato Grosso. 33p.

Turner, D.; Lucieer, A. \& Watson, C. 2012. Na autmated technique for generating georectified mosaics from ultra-high resolution unmanned aerial vehicle (uav) imagery, based on atructure from motion ( $\mathrm{Sfm}$ ) point clouds. Remote Sensing, 4(5): 1392-1410.

An Auken, O.W. 2000. Shrub invasions of North American semiarid grasslands. Annual Review of Ecology and Systematics, 31: 197-215.

Zedler, J.B. \& Kercher, S. 2005. Wetlands resources: status, trends, ecosystem services, and restorability. Annual Review of Environment and Resources, 30: 39-74.

Biodiversidade Brasileira - BioBrasil.

Número temático: Diagnóstico e manejo de áreas úmidas em áreas protegidas

$$
\text { n. 2, } 2019
$$

http://www.icmbio.gov.br/revistaeletronica/index.php/BioBR

Biodiversidade Brasileira é uma publicação eletrônica científica do Instituto Chico Mendes de Conservação da Biodiversidade (ICMBio) que tem como objetivo fomentar a discussão e a disseminação de experiências em conservação e manejo, com foco em unidades de conservação e espécies ameaçadas.

ISSN: 2236-2886 